\title{
Homogeneous Surrogate Virus Neutralization Assay to Rapidly Assess Neutralization Activity of Anti- SARS-CoV-2 Antibodies
}

Sun Jin Kim

University of Utah

Zhong Yao

University of Toronto

Morgan Marsh

University of Utah

Debra Eckert

University of Utah

Michael Kay

University of Utah

Anna Lyakisheva

University of Toronto

Maria Pasic

University of Toronto

Aiyush Bansal

University of Toronto

Hyman Birnboim

https://orcid.org/0000-0001-5830-4769

Prabhat Jha

University of Toronto

Julio Delgado

University of Utah

Marc Elgort

ARUP

Robert Campbell

University of Utah

Elizabeth Middleton

University of Utah

Igor Stagljar

University of Toronto https://orcid.org/0000-0002-5260-3327

Shawn Owen ( $\nabla$ shawn.owen@hsc.utah.edu ) 


\section{Article}

\section{Keywords:}

Posted Date: December 13th, 2021

DOI: https://doi.org/10.21203/rs.3.rs-1105720/v1

License: (c) (1) This work is licensed under a Creative Commons Attribution 4.0 International License. Read Full License

Version of Record: A version of this preprint was published at Nature Communications on July 1st, 2022. See the published version at https://doi.org/10.1038/s41467-022-31300-9. 


\section{Activity of Anti-SARS-CoV-2 Antibodies}

Sun Jin Kim ${ }^{1,+}$, Zhong $\mathrm{Yao}^{2,{ }^{+}}$, Morgan C. Marsh ${ }^{1}$, Debra M. Eckert ${ }^{3}$, Michael S. Kay ${ }^{3}$, Anna Lyakisheva ${ }^{2}$, Maria Pasic ${ }^{4,5,6}$, Aiyush Bansal ${ }^{6}$, Chaim Birnboim ${ }^{6}$, Prabhat Jha ${ }^{6}$, Julio C. Delgado ${ }^{7,8}$, Marc G. Elgort ${ }^{7}$, Robert A. Campbell ${ }^{8,9,10}$, Elizabeth A. Middleton ${ }^{10,11}$, Igor Stagljar $2,12,13,14,15,{ }^{*}$, Shawn C. Owen, ${ }^{1,16,17,{ }^{*}}$

1. Department of Pharmaceutics and Pharmaceutical Chemistry, University of Utah, Salt Lake City, Utah

2. Donnelly Centre, University of Toronto, Ontario, Canada

3. Department of Biochemistry, University of Utah School of Medicine, Salt Lake City, Utah

4. Department of Laboratory Medicine \& Pathobiology, University of Toronto, Toronto, Ontario, Canada.

5. Department of Laboratory Medicine, St. Joseph's Health Centre, Toronto, Ontario, Ontario, Canada

6. Centre for Global Health Research, Unity Health Toronto, University of Toronto, Toronto, Canada

7. ARUP Institute for Clinical and Experimental Pathology, Salt Lake City, Utah

8. Department of Pathology, University of Utah, Salt Lake City, Utah

9. Department of Internal Medicine, Division of General Medicine, University of Utah, Salt Lake City, Utah

10. Molecular Medicine Program, University of Utah, Salt Lake City, Utah

11. Department of Internal Medicine, Division of Pulmonary and Critical Care Medicine, University of Utah

12. Department of Biochemistry, University of Toronto, Ontario, Canada

13. Department of Molecular Genetics, University of Toronto, Ontario, Canada

14. Mediterranean Institute for Life Sciences, Meštrovićevo Šetalište 45, Split, Croatia

15. School of Medicine, University of Split, Split, Croatia

16. Department of Biomedical Engineering, University of Utah, Salt Lake City, Utah

17. Department of Medicinal Chemistry, University of Utah, Salt Lake City, Utah

*igor.stagljar@utoronto.ca ; *shawn.owen@hsc.utah.edu

† equal contribution

The COVID-19 pandemic triggered the development of numerous diagnostic tools to monitor infection and to determine immune response. Although assays to measure binding antibodies against SARS-CoV2 are widely available, more specific tests measuring neutralization activities of antibodies are immediately needed to quantify the extent and duration of protection that results from infection or vaccination. We previously developed a 'Serological Assay based on a Tri-part split-NanoLuc ${ }^{\circledR}$ (SATiN)' to detect antibodies that bind to the spike (S) protein of SARS-CoV-2. Herein, we expand on our previous work and describe a reconfigured version of the SATiN assay that can measure neutralization activity of antibodies directly from convalescent or vaccinated sera. The sensitivity is comparable to cell-based pseudovirus neutralization assays but with significantly shorter preparation and assay run time. As the assay is modular, we further demonstrate that Neutralization SATiN (Neu-SATiN) enables rapid assessment of the effectiveness of vaccines and level of protection against existing SARS-CoV-2 variants of concern and can therefore be readily adapted for emerging variants.

SARS-CoV-2 continues to threaten the world's health as emerging variants of concern have the potential to circumvent deployed vaccines. Simple and rapid serological tests are needed to accurately measure the level and duration of neutralization activity of antibodies that arise from natural infection or vaccination. Currently, there are several FDA-approved serological tests under Emergency Use Authorizations (EUA), 
many of which can detect IgM or IgG against SARS-CoV-2, but do not measure their neutralization efficacy specifically ${ }^{1-3}$. Functional neutralizing antibody titers are often measured with pseudotyped viruses, however, long assay time and discrepancy in published assay protocols have limited their use ${ }^{4-6}$. Alternatively, surrogate virus neutralization assays have been developed to circumvent the use of pseudovirions ${ }^{7-10}$. Although some of these assays have shown successful measurement for serosurveillance of clinical samples, they often resemble ELISA, requiring multiple time-consuming binding and washing steps, while others have not yet reported successful measurement of clinical samples, likely due to the instability of recombinant proteins in serum and plasma. Here, we report the development of a homogeneous surrogate virus neutralization assay (hsVNA) called "Neu-SATiN" by reconfiguring our previously designed serological assay (Serological Assay based on split Tri-part Nanoluciferase; SATiN) ${ }^{11}$ to quantify the degree of neutralization from antibodies directly from plasma or serum.

In our previous report, we developed SATiN as a homogeneous serological assay platform that utilizes a tri-part NanoLuc ${ }^{\circledR}$, which is split into two small peptide tags, b9 and b10 (each about $1 \mathrm{kDa}$ ), and one large fragment, $\Delta 11 \mathrm{~S}$ (18 kDa). Using the same tri-part NanoLuc ${ }^{\circledR}$, we now show the development of a homogeneous neutralization assay version of SATiN (Neu-SATiN). In Neu-SATiN, enzyme fragment peptides, b9 or b10, are fused to the ACE2 receptor, the target of infection, and to the SARS-CoV-2 spike (S) protein. We hypothesized that when the ACE2 and the S proteins interact, the fused split-NanoLuc ${ }^{\circledR}$ fragments are driven to within $\sim 100 \AA$ of each other, allowing $\Delta 11 \mathrm{~S}$ to reconstitute into fully functional NanoLuc ${ }^{\circledR}$. Importantly, when the interaction between the ACE2 and S proteins are blocked by neutralizing antibodies, the tags are prevented from interacting and subsequent complementation of NanoLuc ${ }^{\circledR}$ is blocked (Fig 1a). In Neu-SATiN, the level of neutralization correlates with the decrease of luminescence. As the assay is intentionally modular, full-length ectoderm of the S protein of SARS-CoV-2 variants of concern can be quickly produced and swapped with wild type $S$ protein to assess immunological protection. Moreover, as Neu-SATiN is designed to be a "mix-and-read" assay, the actual hands-on time is less than 30 minutes, significantly improving turnaround time.

a)

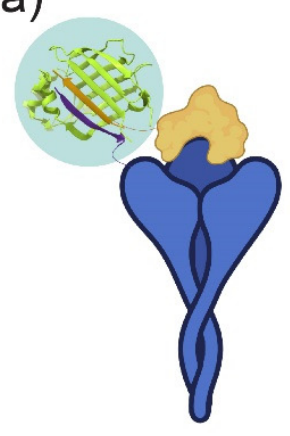

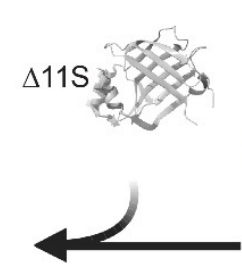

Binding enables luciferase complementation
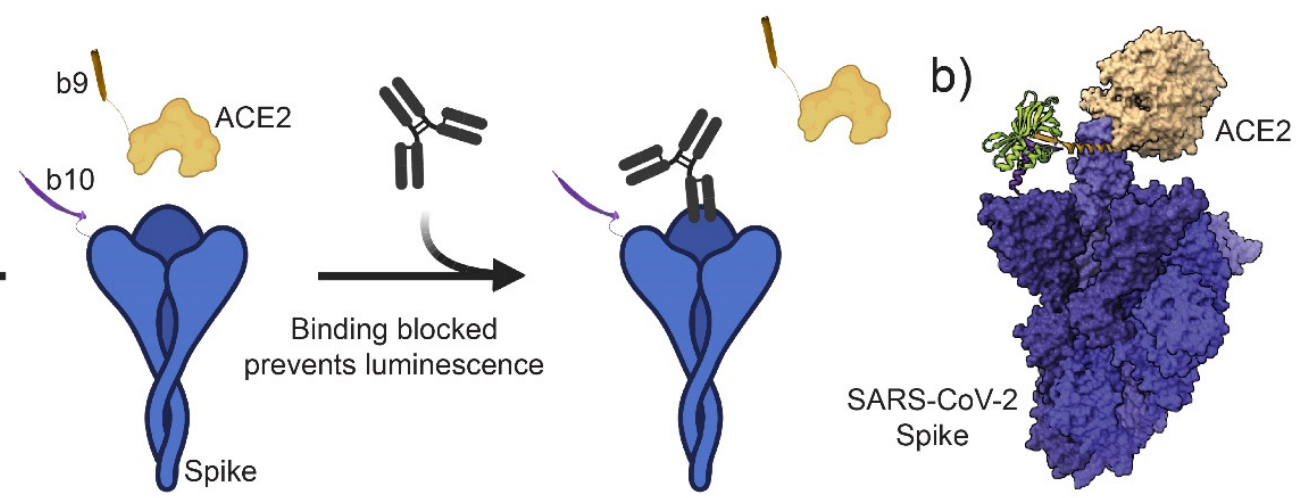

Fig 1. General schematic of the Neu-SATiN COVID-19 neutralization assay and molecular modeling of spike (S) protein and ACE2 interaction. a) Tri-part NanoLuc ${ }^{\circledast}$ peptide fragments are individually fused to recombinant $S$ protein (purple) and ACE2 ( $\tan )$. Interaction of S protein and ACE2 induces complementation of the split-luciferase and 'turns on' luminescence (left). In the presence of neutralizing antibodies, the interaction between S protein and ACE2 is blocked, preventing luminescence (right). Figure generated using BioRender. b) Molecular model of the predicted refolding of NanoLuc ${ }^{\circledR}$ (PDB ID: 5IBO) is shown (green) after complementation of fragments b10 and b9 is driven by the interaction between full spike protein (trimer) and ACE2 (PBD ID: 7A97). 
We considered three options for fusing the split-luciferase fragments to the SARS-CoV-2 spike (S) protein and its target, the human ACE2 receptor: 1) N-terminus, 2) C-terminus, or 3) both termini. Although surface loops are possible fusion points, modifying these domains may interfere with neutralizing antibody binding. Based on our previous experience, we know that reconstitution of split-NanoLuc ${ }^{\circledR}$ is most efficient when the fusion locations are within $~ 50-100 \AA^{12-14}$. We used molecular modeling to determine possible fusion points on S protein and ACE2 that place fragments within this proximity (Fig 2a and Fig 3a).

To test feasibility, we initially built the system using only the receptor binding domain (RBD) of the SARSCoV-2 spike protein and ACE2. Based on molecular modeling of RBD and ACE2 (Fig 2a) ${ }^{15}$, the distance from the $\mathrm{N}$-terminus of ACE2 to the $\mathrm{N}$-terminus of RBD is $\sim 60 \AA$ and to the C-terminus is $\sim 53 \AA$ (PBD ID: 6MOJ). In contrast, the C-terminus of ACE 2 is more than $100 \AA$ away from either terminus of RBD and thus was excluded as a potential tag fusion site. The complete list of binders used in this study is listed in Extended Data Table 1. Using purified recombinant proteins, we confirmed that the engineered RBD and ACE2 binders with complementary tags produced detectable luminescent signal when combined with the large fragment of the split luciferase, $\Delta 11 \mathrm{~S}$, in human serum. Each binder combination shows substantial luminescence; however, there are differences in signal-to-background ratios (Extended Data Fig 1a). We also confirmed substantial decrease in the signal when the binders were incubated with neutralizing antibody (NAb) (Sino Biological, 40592-MM57), indicating inhibition of RBD binding to ACE2 to prevent complementation of the split-luciferase fragments. For any given pair, the fractional decrease in luminescent signal as a function of increasing concentration of NAb displays a typical dose-response curve for inhibition that is specific to the NAb (Extended Data Fig 1b). This suggests that, although the maximum signal intensity produced by each binder pair is different, the proportional decrease in the signal in the presence of NAb is similar. Therefore, the ability to measure NAB antiviral activity is feasible with several different pairs. We characterized binder pairs further by calculating $\mathrm{IC}_{50}$ of the NAb using each pair and stability of the complex in high concentrations of non-binding IgG (Extended Data Fig $1 \mathrm{c}$ and $1 \mathrm{~d}$ ). We selected the pair (S)RBD-b9 and b10-ACE2 based on the lowest discrepancy in $\mathrm{IC}_{50}$ value compared to the manufacturer's report and in resolving concentration to response.

After validating Neu-SATiN's ability to detect NAb activity, we validated the assay with clinical plasma samples from actively infected (from ICU) and convalescent patients $(n=18)$. The plasma samples were tested and binned into 5 different groups in respect to their relative luminescence compared to the control NAb (Fig 2d). Of the convalescent patient samples (PS 16, 17, 18), patient sample 17 (PS 17) showed inhibition similar to $100 \mu \mathrm{g} / \mathrm{mL}$ of the control NAb. PS 16 and PS 18 were not as effective as PS 17, but still showed significant decrease in luminescence intensity compared to $0 \mu \mathrm{g} / \mathrm{mL}$ of NAb. As the neutralization activity depends on the epitope, affinity and concentration of the antibodies, the comparison between the control antibody and the antibodies in patient plasma is only relative. Nevertheless, our data confirm that Neu-SATiN is able to distinguish the presence or absence of antiviral antibodies and quantify the relative level of neutralization directly in clinical samples (Figure 2). 

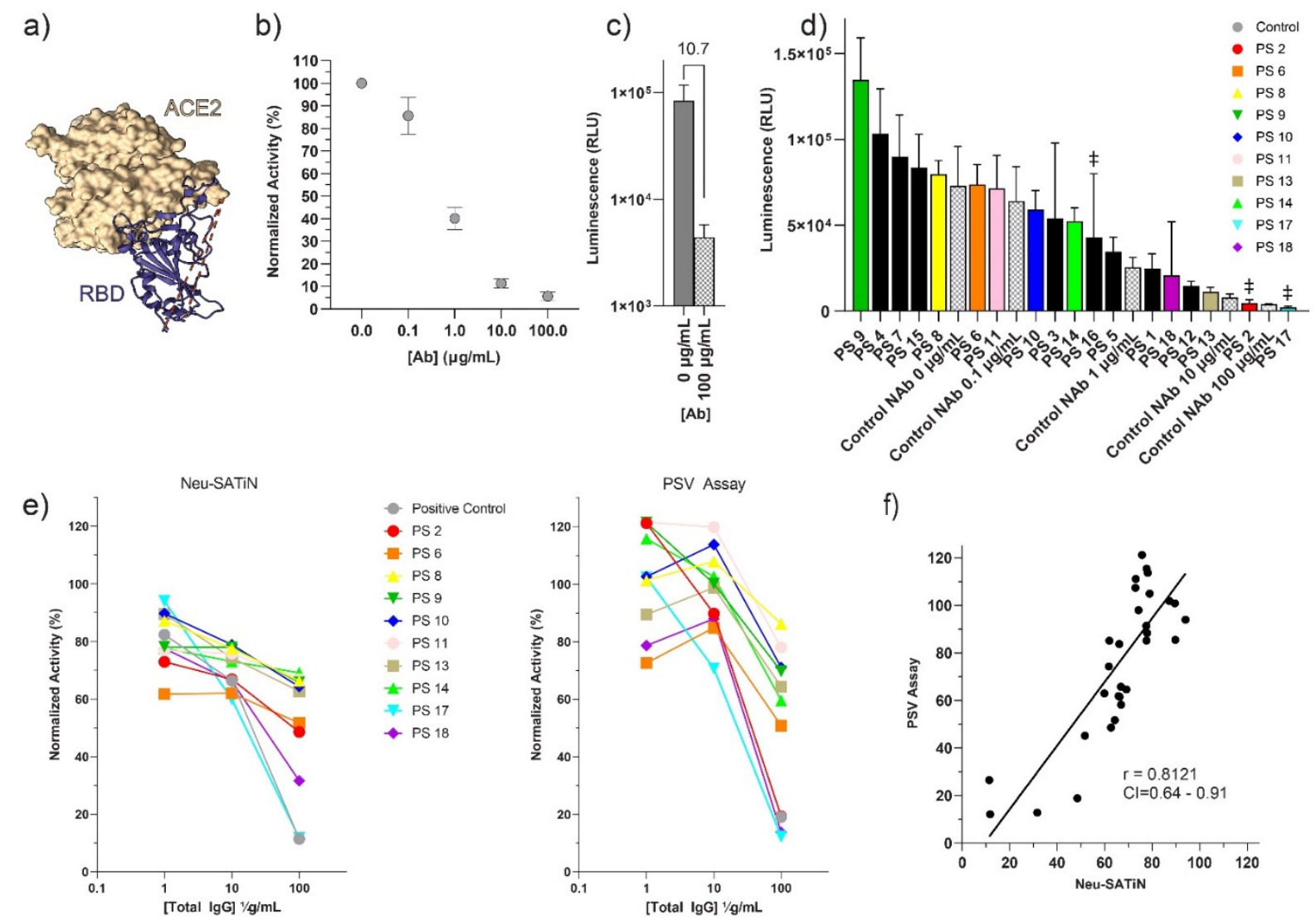

f)

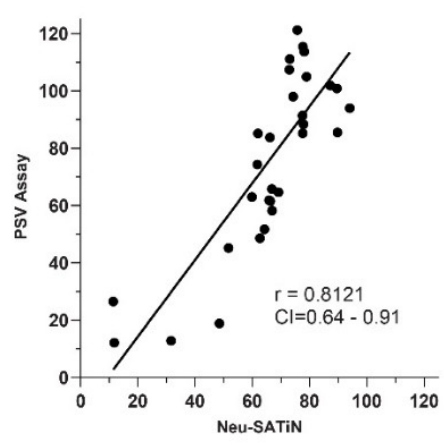

Fig 2. Binder pair screening in human serum and patient samples (PS 1-18). a) Molecular modeling of the distances between $\mathrm{N}$-terminus of ACE2 to the $\mathrm{N}$-terminus of RBD is $\sim 60 \AA$ and to the C-terminus is $\sim 53 \AA$ (PBD ID: 6MOJ). As such, luciferase fragments can be fused at either terminus of RBD and N-terminus of ACE2. b) (S)RBD-b9 and b10-ACE2 binder pair was screened with increasing concentrations of neutralizing Ab (NAb, Sino Biological 40592-MM57) in human serum. c) Using (S)RBD-b9 and b10-ACE2 binder pair, the signal between $0 \mu \mathrm{g} / \mathrm{mL}$ of NAb (darker color) vs. $100 \mu \mathrm{g} / \mathrm{mL}$ of NAb (lighter color adjacent bar) shows a 10-fold decrease upon neutralization. d) Testing 18 patient plasma samples: (S)RBDb9 and b10-ACE2 were mixed directly with plasma samples, followed by the addition of the detection solution ( $\triangle 11 \mathrm{~S}$ and substrate). Samples 16,17 , and 18 (indicated by $\ddagger$ above bar) are known to be convalescent whereas other samples are from ICU patients with unknown antibody presence/levels. Representative samples (colored) were carried forward to test titer. e) IgG was purified from the patient plasma samples and serially diluted to mimic plaque-neutralization and other assays, then tested with Neu-SATiN (left) $\mathrm{N}=4$ and also with PSV assay (right) $\mathrm{N}=4$. Average activity shown (symbols), CV is $\leq 0.15$ for each sample (not shown) f) Average signals from each assay were plotted and show high correlation between the two assays with an $r$ value of 0.8121 . NAb was used as an internal positive control.

Next, we compared Neu-SATiN to a pseudovirus neutralization (PSV) assay based on a human immunodeficiency virus (HIV) system with luciferase gene reporter. As PSV assays are sensitive to protein content and often require dilution of clinical samples (typically one-half dilutions or more) with specific matrix (e.g., cell culture compatible media and buffer), performing the assay using direct plasma samples was not feasible. Instead, we selected ten samples (non-black bars on Fig $2 \mathrm{~d}$ ) and extracted plasma IgG using protein $\mathrm{G}$ magnetic beads. The purified samples were serially diluted and tested with PSV assay (Fig 2e right). The results obtained from Neu-SATiN and PSV assay show good correlation (Pearson's $r$ value of 0.81), with better correlation at higher IgG concentrations. Both PSV assay and Neu-SATiN showed that PS 17 had the highest inhibition activity similar to the positive control (IgG purified from commercial human serum spiked with $100 \mu \mathrm{g} / \mathrm{mL} \mathrm{NAb}$ ). One potential source of discrepancy seen between the results is lack of IgMs in PSV assay. Protein $G$ is effective only in purifying IgGs, therefore purified clinical plasma mainly contained IgGs to be tested on PSV assay. As Neu-SATiN is performed directly using whole plasma, the antiviral activities of both IgGs and IgMs may contribute to the level of inhibition. 
Even though many of the antibodies produced by current vaccines target the RBD of S protein ${ }^{16,17}$, the more pressing concern is protection against variants of concern which often have mutations outside of the RBD. ${ }^{18,19}$ In response, vaccines are being developed to target full-length $S$ protein ${ }^{20}$. As such, we expanded Neu-SATiN using ACE2 and the full ectodomain of S protein, including known amino acid substitutions stabilize conformation ${ }^{21}$. The rationale for using full-length $\mathrm{S}$ protein should provide a more comprehensive measurement of the neutralization effect. Molecular modeling was used again to examine the distances between the termini of two proteins (Fig 3a) using PBD ID: 7A9722. Based on this analysis, we decided to fuse b10 to the N-terminus of S protein and b9 to the N-terminus of ACE2. The length of linker connecting the proteins to the tags was also doubled from nine to eighteen amino acids to increase the flexibility of the tags and to encompass a broader range of potential binding confirmations. Consistent with previous studies ${ }^{23}$, we found the interaction between S ectodomain and ACE2 monomer is relatively low, likely due to ACE2 instability, and decided to use a dimerized ACE2 binder created by fusing the ACE2 $\mathrm{N}$-terminal domain (a.a. 16-614) with the human IgG Fc fragment (Extended Data Table 1). These two proteins, denoted as "b10-(S)-WT" and "b9-ACE2-Fc", were validated for binding-induced luminescence (Fig 3b). The full wild-type spike protein (WT) version of the binder pair shows average luminescence signal of $1.6 \times 10^{6} \mathrm{RLU}$ indicating successful complementation of the split-NanoLuc ${ }^{\circledR}$ fragments and shows a robust 3000-fold signal-to-background ratio. We produced mutated S proteins for each of the major SARSCoV-2 variants of concern: Alpha, Beta, Gamma, and Delta ${ }^{18,19}$ (mutation sequences in Extended Data Table 2). The mutations were made throughout the ectodomain of $S$ protein and not just limited to the RBD. Additional mutations were made to the furin cleavage site to prevent unwanted degradation of the binders by cell culture proteases and to enable purification of recombinant proteins ${ }^{24,25}$. The orientation of the tags on each protein were kept the same: b10-(S)-Variant and b9-ACE2-Fc. All four variants (Alpha, Beta, Gamma, and Delta) produced distinct luminescence signals with high signal-to-background (Fig 3b). The neutralization of the WT pair (WT S protein with ACE2) corresponds well with concentrations of a NAb (Sino Biological, 40592-R001) (Fig 3c); however, there was limited neutralization of most of the variants using this NAb (Extended Data Fig 2).

We obtained another set of serum samples $(n=43)$ that have been tested with two different Emergency Use Authorized COVID-19 S protein binding antibody assays: 1 ) COV2G Siemens $1^{\text {st }}$ Gen (target antigen: RBD, cutoff: $\geq 1.0$ ), and 2) EUROIMMUN (target antigen: S1, cutoff: $\geq 1.1$ ). The samples can be further categorized into three different groups: 1) SARS-CoV-2 exposed with no vaccination history (post-infection, Samples 1 - 18), 2) SARS-CoV-2 exposed with vaccination history (post-infection and post-vaccination, Samples $19-28$ ), and 3) neither exposed nor vaccinated (no infection and no vaccination, Samples 29 43). All of the samples were screened with our full-length-WT S protein Neu-SATiN for the presence of neutralizing antibodies. Commercial human serum spiked with NAb (Sino Biological, 40592-R001) was used as a positive control and to determine relative neutralization activity of the patient samples. (Fig 3d - indicated by red dotted line) in Neu-SATiN, with the exception of Sample 2 (frequency $=27 / 28$, $96 \%)$. These were also the samples that scored $>20.00$ in Siemens $1^{\text {st }}$ Gen and $>8$ in EUROIMMUN EIA, both indicating the presence of anti-SARS-CoV-2 antibodies against the WT S protein. Intriguingly, when the patients were previously infected and then vaccinated (Samples 19-28, $n=10$ ), their sera showed normalized activity scores of 0.05 or below (frequency $=10 / 10,100 \%$ ). The various levels of neutralization shown in Samples $1-18$ are possibly due to difference in sample collection day post-infection, as it is known that antibodies levels are highest 4-5 weeks after symptom onset ${ }^{26,27}$. Conversely, all SARS-CoV-2 negative patients (Samples 29-43, $n=15$ ), based on standard antibody test, showed signals above 0.1 (frequency $=15 / 15,100 \%$ ), indicating no neutralization activity. 
a)

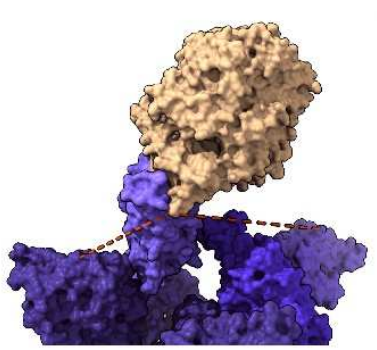

d) b)

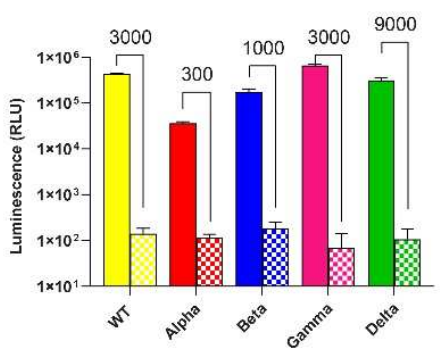

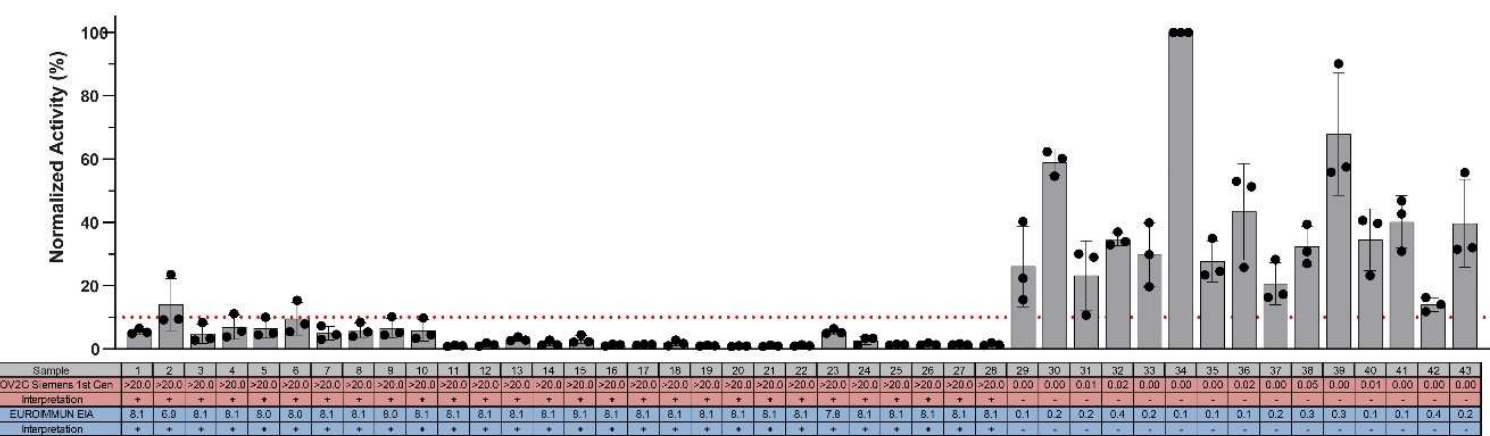

c)

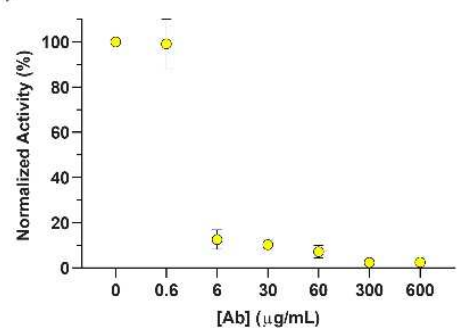

e)

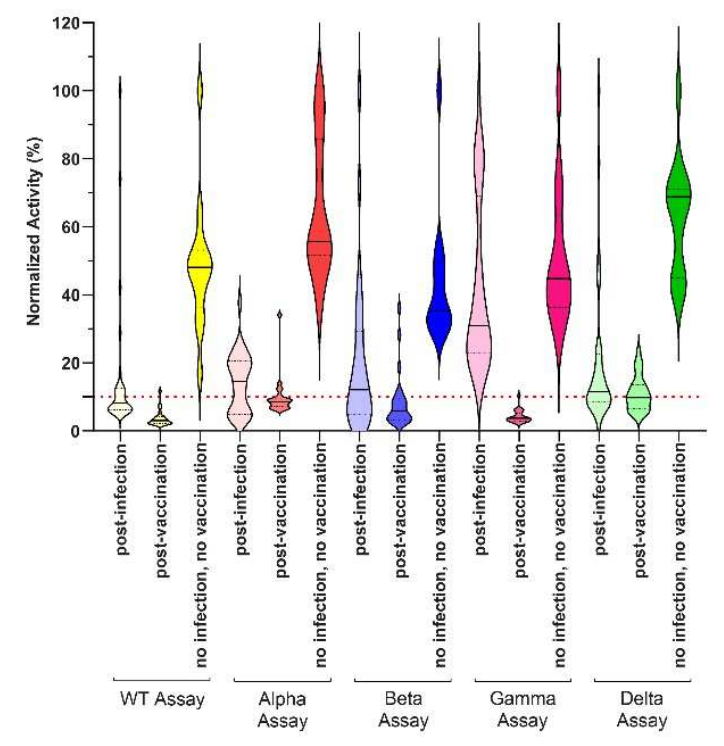

f)

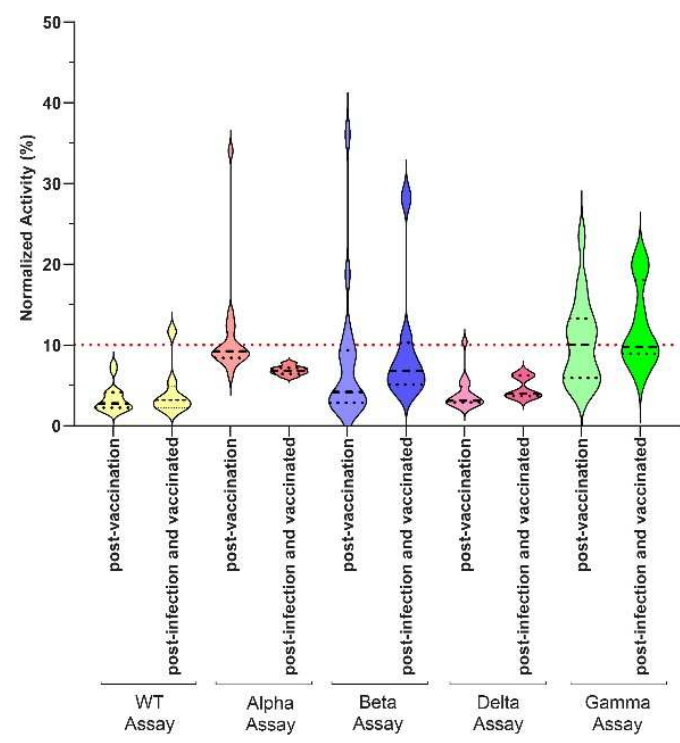

Fig 3. Validation of full spike proteins (wild type and variants) and ACE2 binders in the serosurveillance of clinical samples. a) Molecular modeling of the distances between N-terminus of ACE2 to the N-termini of nearest S protein is $\sim 48 \AA$ and $\sim 88 \AA$, respectively (PBD ID: 7A97). b) Comparison of signal and background for the full spike (wild type and variants) and ACE2 pairs. c) Serial dilution of a commercially available NAb (Sino Biological, 40592-R001) in the presence of b10-(S)WT and b9-ACE2-Fc pair. d) Serum samples that have been tested previously on two different COVID-19 detection kits were also tested on NeuSATiN. Wild type full spike protein with b10 tag (b10-(S)WT) and ACE2 with b9 tag (b9-ACE2-Fc) were used as the binders. Signals from patient samples were normalized to the signal from normal human serum just with the binders (no neutralizing antibodies). The scaled data for individual sample were plotted where the red dotted line at $10 \%$ (i.e. $90 \%$ neutralization) indicates the cutoff line to distinguish neutralizing samples from the non-neutralizing samples. Bottom table shows the results from two prior tests detecting anti-SARS-CoV-2 antibodies (COV2G Siemens $1^{\text {st }}$ Gen and EUROIMMUN EIA) for corresponding individual samples; interpretation, indicated either as positive (+) or negative (-), denotes the presence of anti-SARS-CoV-2 antibodies. e) Neutralization efficacy of patient samples against WT and variant S proteins. Samples used in Fig $3 d(n=43)$ were tested with an additional $n=35$ patient samples that were positive for anti-SARS-CoV- 2 antibodies. Luminescence signals from each patient serum were normalized to the signal from corresponding binder pair in commercial human serum (no NAb). Then, the highest value in each set was used to compute normalized activity. Known post-vaccination, post-infection, and negative (no known infection or vaccination) samples were plotted separately. Red dotted line at $10 \%$ indicates the cutoff between the negative samples and the positive samples for distinction of neutralization. $\mathrm{f}$ ) Comparison of serum data based on patients that were vaccinated to patients that were vaccinated following a reported infection $(n=40)$. 
Altogether, the data supports that our newly developed Neu-SATiN neutralization assay is a reliable surrogate test that shows congruent results compared to already established tests. As we recognize that immunities generated by vaccination versus infection are known to produce antibodies targeting different parts of $\mathrm{S}$ protein ${ }^{28}$ and that the protection against variants based on vaccination and/or previous infection additional set of infected patients $(n=35)$, for the samples' neutralization efficacies towards different variants of concern. Since a universal NAb that can neutralize WT and all variants is not available, we were not able to determine relative degree of neutralization compared to a known concentration of NAb for each of the variants, but only for the WT. Instead, we compared fractional decrease in luminescence signal from the positive samples to negative samples for each variant pair; the highest signal observed from the negative group was considered $100 \%$ activity (i.e., no decrease in signal) and subsequent decrease in signal was determined for the positive groups. As shown in Fig 3e, the NAb negative samples (darkest color violin plots) tend to display a wide range of signal compared to the NAb positive groups. Overall, the mean fractional signal observed from the positive samples (post-infection or post-vaccination) tested either with WT or variant pairs were $10 \%$ or lower. In other words, the signal measured from the positive samples were less than $10 \%$ of the signal from the negative group. This suggests that most of the samples within the positive groups have some level of neutralization ability towards each of the variant SARS-CoV-2s. In particular, both WT and Gamma variant were neutralized almost fully by immunity generated by vaccination; however, there appears to be a subset of samples within the Delta, Alpha, and Beta variant groups with minimal neutralization even after infection and/or vaccination (Fig 3f). It was also interesting to note that natural immunity generated by infection with SARS-CoV-2 was not sufficient to neutralize the Gamma variant and that vaccination was required for stronger neutralization (Fig 3e). This observation is potentially due to antibodies produced by different immunities targeting different parts of $\mathrm{S}$ proteins and can cause differences in recognizing mutation sites ${ }^{28,29}$. Without further information on which vaccines were received by these patients or the sample collection dates post onset of symptoms, we are not able to determine the exact correlation between vaccination and difference in protection against variants.

We next sought to expand on our observations and tested serial dilutions of FDA EUA approved neutralizing antibodies Regn10933 (casirivimab), Regn10987 (imdevimab), and JS016 (etesevimab), as well as sera with known vaccination history $(n=24)$. Having such data is informative in detecting the lowest effective concentrations (titers) and therefore determining the potency of NAbs. Of the FDA EUA antibodies, imdevimab was the most effective against all variants of the $S$ protein. The other two antibodies, casirivimab and etesevimab, were most potent against WT but showed variable potency against variant $\mathrm{S}$ proteins. There was no effective neutralization observed for the Beta strain with either antibody (Fig 4a). For the serosurveillance of patient samples (Fig 4b), no neutralizing activity was observed in patients that were not vaccinated, as expected. The patients with one dose showed negligible potency compared to the patients with two doses with samples collected $<50$ days after the last dose. For samples collected $>50$ days after receiving two doses, the potency of antibodies significantly reduced as indicated by shift in titration curve towards the right, consistent with recent reports of waning immunity for some vaccines ${ }^{30}$. In quantifying these patient samples in terms of the $50 \%$ neutralization titer (Fig 4c), the majority show strong neutralization against WT and the least potency against Beta variant, with the other variants of concern intermediate. 
a)
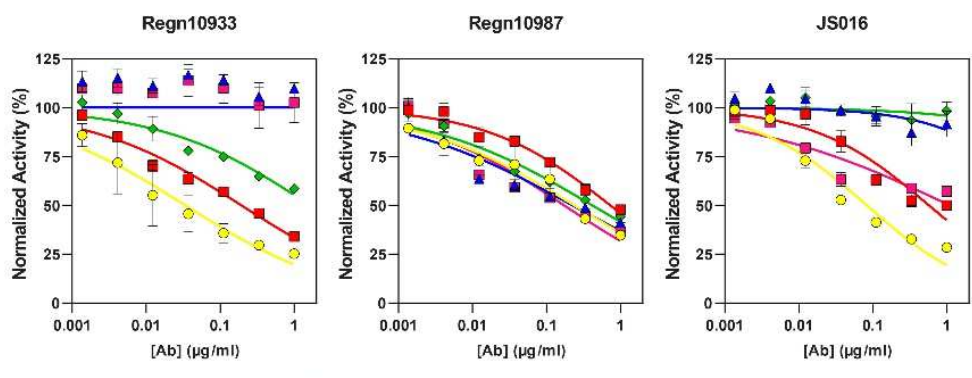

b)

$\circ$ WT $\Rightarrow$ Alpha $\quad$ Beta $\rightarrow$ Gamma $\rightarrow$ Delta

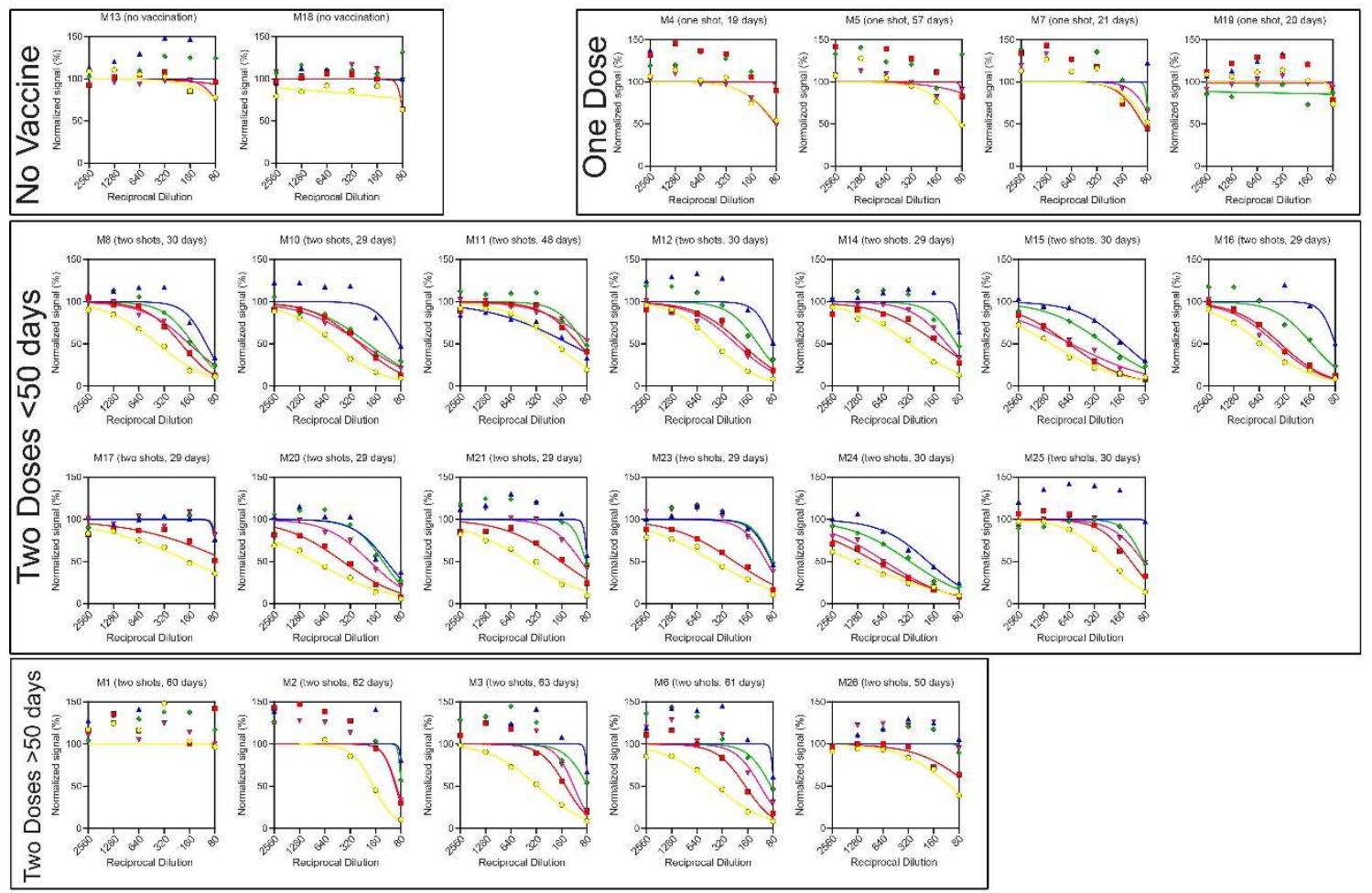

c)

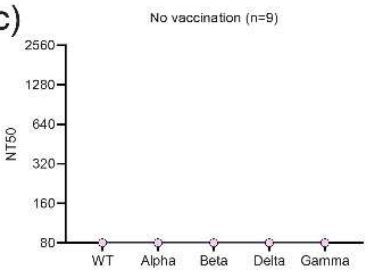

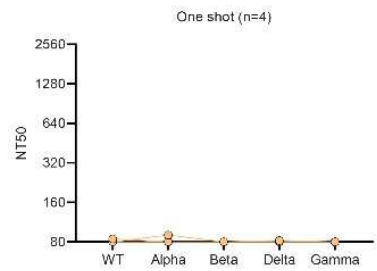
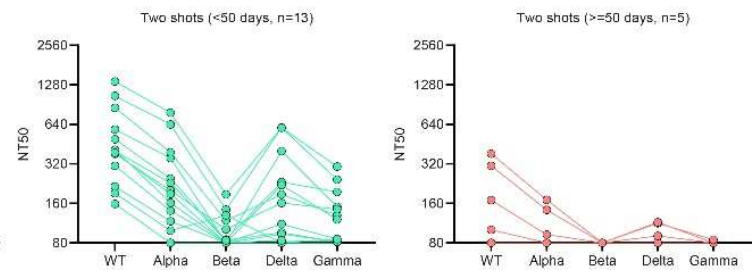

Fig 4. Assessing the potency of neutralizing antibodies. a) Neutralizing capabilities of FDA EUA approved therapeutic antibodies Regn10933 (left, casirivimab), Regn10987 (center, imdevimab), and JS016 (right, etesevimab) were evaluated using Neu-SATiN against different $S$ variants. b) Evaluation of neutralizing antibodies in individuals with unvaccinated sera $(n=2)$, with one vaccination dose $(n=4)$, with two vaccination doses and collected within 50 days after the second shot $(n=13$, intervals between shots were 21-37 days), and with two vaccination doses collected more than 50 days after the second shot ( $n=5$, intervals between shots were 21-36 days). c) Aggregated data showing titers at 50\% neutralization (NT50) for each group.

\section{DISCUSSION}

Since the outbreak of the COVID-19 pandemic, the importance of a virus neutralization assay has risen more than ever. Virus neutralization assays are the main tools for developing vaccine and therapeutic strategies ${ }^{31-33}$. Although the PSV assay is effective in measuring the degree of infection, maintaining cell cultures and making pseudovirus particles are labor intensive with potential safety concerns ${ }^{34}$. Moreover, 
batch-to-batch variability in virus production and cell transfection efficiency limit standardization and robust assay results ${ }^{35}$. Numerous immunoassays for rapid detection of anti-SARS-CoV-2 antibodies have been developed, however, these assays mainly focus on capturing and detecting antibodies binding to virus proteins (e.g., spike or nucleocapsid) ${ }^{2}$. Since it is well known that mere binding does not necessarily imply neutralization ${ }^{36}$, a true neutralization assay for the better understanding of protective immunity against SARS-CoV-2 is needed. To circumvent the use of virus particles and cells, surrogate versions of neutralization assays have been developed ${ }^{7-9}$. These assays often use ELISA or similar platforms, with multiple time-consuming binding and washing steps, preventing high-throughput screening ${ }^{37}$. In need of an accurate yet more rapid virus neutralization assay, we developed a homogeneous surrogate virus neutralization assay called Neu-SATiN, using a split-luciferase system.

In the initial design of the assay, similar to the first report using a complementation assay, we investigated ACE2-RBD interactions ${ }^{10}$. By using a tri-part split-luciferase platform, we show for the first time that monitoring the decreased interaction of ACE2 receptor with RBD of spike protein was sufficient to quantify the neutralization activity of patient plasma (Fig. 2). The result is in agreement with widely reported NAb and RBD interaction: the neutralization activities of NAb mostly come from anti-RBD immunoglobulins ${ }^{36,}$ 38. Importantly, the results from Neu-SATiN were comparable to the results from PSV assay with a Pearson's r value of 0.81 (Fig 2f). Given that these assays were tested in different matrices (full plasma vs. PSV assay cell culture media), this correlation value is very high.

The importance of conformational changes in spike protein altering ACE2 binding has been emphasized in many studies ${ }^{22}$, 39 . Also, with new variants of concern emerging, many of the deployed vaccines and second-wave vaccines in development are targeting full spike protein ${ }^{40-42}$. Immunologic response to these vaccines may produce antibodies against epitopes outside of the RBD and may require the trimeric structure of the full spike protein for binding. This compelled us to develop stabilized, full-length-spike (both WT and major variants of concern) versions of the binders and stable, dimerized ACE2 receptor. The data presented in Fig. 3 demonstrates that b10-(S)WT/ b9-ACE2-Fc can differentiate the degree of neutralization directly from patient sera and that variant versions of the spike binders can distinguish antiSARS-CoV-2 NAb positive serum samples from negative samples (Fig 3e,f). In addition, Neu-SATiN can provide quantitative analysis of NT50 and thus enables the measurement of potency of anti-SARS-CoV-2 antibodies against different strains (Fig 4). Combined, this provides a comprehensive screen of a patient's level of protection against the current variants of concern. As the assay is modular, emerging variants of interest can be quickly produced and incorporated.

In summary, the results obtained with Neu-SATiN correlate with HIV-based PSV assay and other antigenbased assays. One advantage of Neu-SATiN is that it can be performed homogenously and directly using plasma or serum, which significantly reduces hands-on assay time to $<30 \mathrm{~min}$ and can be run under

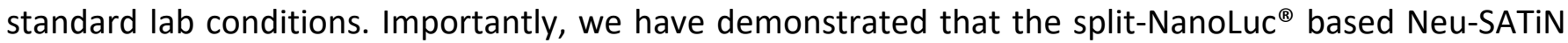
can be applied to full-length spike proteins of the original strain and variants to test neutralization levels of convalescent patient sera. Having a modular technology as a surrogate assay that can be easily adopted as a point-of-care tool is important in tracing and adapting to the evolution of the current pandemic.

\section{METHODS}

\section{Cell culture media, antibodies, and, cloning reagents,}

HEK293 cell culture reagents were purchased from Thermo Fisher Scientifics. Two neutralizing antibodies: 40592-MM57 (used for RBD pair screening) and 40592-R001 (used for WT pair screening) were both purchased from Sino Biological. Regn10933 (CPC511A), Regn10987 (CPC512A) and JS016 (CPC516A) were purchased from Cell Sciences. 
Samples were obtained from either the University of Utah School of Medicine, ARUP Laboratories, or from Unity Health. University of Utah School of Medicine (total $n=16$ ) were obtained from infected patients within $48 \mathrm{~h}$ of admission to ICU $(n=13)$ or within 3-5 weeks of positive PCR test for convalescent patients $(n=3)$. Samples for determining neutralization (total $n=63$ ) in uninfected, infected and/or vaccinated were generously provided by ARUP Laboratories (IRB approved protocol 0007740). Samples for antibody titer and serosurveillance studies (total $n=24$ ) were collected from Unity Health employees, enrolled through (REB approved protocol REB 20-107, Toronto). All samples were deidentified.

328 329 330 331 332 333 334 335 336 337 338 339 340 341 342 343 344 345 346 347 348 349 350 351 352 353 354 355 356 357 358 359 360 361 362 363 364 365

\section{Vector Construction and Transient Transfection in HEK293 Cells}

Vector cloning for the binder expression was performed as previously described ${ }^{11}$. Briefly, all cDNA were cloned into an in-house mammalian expression vector derived from pCMV5 with a signal peptide sequence appended at the $\mathrm{N}$-termini and an octa-histidine stretch at the $\mathrm{C}$-termini. For the constructs that had the tag at the N-termini, either b9 or b10 sequence was placed after the signal peptide, followed by the binder sequence. Likewise, the constructs with C-terminus tag had b9 or b10 sequence right before octa-histidine (Extended Data Table 1). The final products were transfected into HEK293 cells using polyethylenimine Max (Polysciences).

\section{Production and Purification of Binders}

HEK293 cells transfected with binder constructs were cultured in DMEM supplied with 10\% FBS and 1X antimycotic-antibiotic mixture. Typically, cells were seeded at 50\% confluency, and the media was collected every day until the cells became fully confluent. The collected media was filtered through 0.22 $\mu \mathrm{m}$ PES filter before purification. Purification was done on AKTA FPLC using HisPur ${ }^{\mathrm{TM}}$ Cobalt Resin. Tween$20(0.01 \%)$, trehalose $(0.1 \%)$, and glycerol $(10 \%)$ was added to the final product and kept at $-80{ }^{\circ} \mathrm{C}$ before use.

\section{Reconstitution of Split-NanoLuc ${ }^{\circledR}$ Driven by (S)RBD and ACE2 interaction}

For the screening of (S)RBD binders with ACE2 binders, the neutralizing antibody (Sino Biological, 40592MM57) spiked in commercial human serum ( $10 \mu \mathrm{L}$ in various concentrations) was combined with $5 \mu \mathrm{L}$ of (S)RBD binders (10 pmol) and $5 \mu \mathrm{L}$ of ACE2 binders (10 pmol), and incubated for $30 \mathrm{~min}$. The incubation was done using white, round bottom 96 -well plates at room temperature with vigorous shaking. Then, the "detection solution" which consists of coelentrazine (substrate) and $\Delta 11 \mathrm{~S}$ was premixed, and $80 \mu \mathrm{L}$ of the detection solution was added to each well. The final concentrations of the substrate, coelentrazine, was $10 \mu \mathrm{M}$ and the large enzyme fragment, $\Delta 11 \mathrm{~S}$, was $500 \mathrm{nM}$ per well in a total volume of $100 \mu \mathrm{L}$. Luminescent signal was measured using TECAN Infinite M1000Pro in a kinetic cycle. The results reported here are from the 30-min timepoint.

\section{Split NanoLuc ${ }^{\circledR}$-based Virus Neutralization Assay: Testing Spiked Samples and Convalescent Samples}

Measuring neutralization activity of clinical samples was done in a similar fashion as described above: 10 $\mu \mathrm{L}$ of clinical sample with 10 pmol of Spike protein ( $5 \mu \mathrm{L}$; full S or (S)variant) and 10 pmol of ACE2 fusion $(5 \mu \mathrm{L})$. All three components were incubated together for $30 \mathrm{~min}$ with vigorous shaking. Then, $80 \mu \mathrm{L}$ of the detection solution (defined above) was added (final total volume per well was $100 \mu \mathrm{L}$ ) and the kinetic cycle of luminescent was measured. For serial dilutions to quantify activity of low titer samples, the assays were performed in a buffer containing $20 \mathrm{mM}$ Tris ( $\mathrm{pH}$ 7.5), 0.1\% Tween 20, $2 \mathrm{mM}$ TCEP, 2mM EDTA, 25 $\mathrm{mM} \mathrm{NaCl}$ and $0.05 \% \mathrm{BSA}$. Serum samples $(12.5 \mu \mathrm{L})$ were first diluted in a volume of $50 \mu \mathrm{L}$ of buffer, 
followed by additional one-half serial dilutions up to 6 times. An aliquot $(5 \mu \mathrm{L})$ of the diluted sample was mixed with $5 \mu \mathrm{L}$ of b10 modified S binder ( $20 \mathrm{nM}$; full S or (S)Variant) and incubate for 30 minutes. An aliquot $(5 \mu \mathrm{L})$ of the reaction mixture was further mixed with $45 \mu \mathrm{L}$ of substrate mixture containing 555.6 nM b9-ACE2-Fc, $100 \mathrm{nM} \Delta 11 \mathrm{~S}, 22.2 \mu \mathrm{M}$ furimazine (substrate). After $1 \mathrm{hr}$ incubation, luminescence signals were measured using a microplate reader. The inhibition curve of a sample against $S$ protein variant was obtained by fitting the readings at different dilutions into the normalized response model with variable slope in GraphPad. The titer of 50\% neutralization was calculated according to each model.

\section{Testing Spiked Samples and Convalescent Samples with Pseudovirus Neutralization (PSV) Assay}

The active sera (from patients in ICU) and convalescent sera were purified using protein $\mathrm{G}$ magnetic beads (Promega Corporation, G7471) as per manufacturer's instruction. The concentrations of purified IgG were measured using NanoDrop 2000. Pseudovirions were produced by co-transfecting 293T human embryonic kidney cells using PEI transfection reagent (Polysciences, Inc., Warrington, PA) with NL4-3 HIV-1 genome (pNL4-3.Luc.R-E-, including the firefly luciferase gene inserted into the nef coding sequence and frameshift mutations in Env and Vpr) and a plasmid encoding the desired virus fusion protein (pCAGGS-SARS2-S-cFlag D614G, kind gift of M. Farzan ${ }^{43}$ for SARS-CoV-2 S or pMDG VSV-G for VSV as a specificity control). Forty hours post-transfection, pseudovirus-containing supernatant was filtered $(0.45 \mu \mathrm{M})$ and concentrated by ultracentrifugation (26,000 RPM, 2 hours) through a 20\% sucrose/TNE (10 mM Tris pH 7.6, $100 \mathrm{mM} \mathrm{NaCl}$, $1 \mathrm{mM}$ EDTA) cushion, and the pellet resuspended in TNE, aliquoted and stored at $-80 \mathrm{C}$. To measure inhibition of infectivity, $50 \mu \mathrm{L}$ of $2 \times \mathrm{IgG}$ (purified from patient sera) diluted in media was added to CaLu-3 cells (ATCC HTB-55) in a 96-well format, each concentration in triplicate. $50 \mu \mathrm{L}$ of pseudovirus diluted in media $+16 \mu \mathrm{g} / \mathrm{mL}$ DEAE-dextran was added and plates were spinoculated at $2100 \times \mathrm{g}, 30 \mathrm{~min}, 10^{\circ} \mathrm{C}$. At 20 hours, virus and inhibitor were removed via aspiration, and fresh media was replenished. At 40 hours, the cells were lysed, and the luciferase activity was measured (Bright-Glo luciferase assay system, Promega, Madison, WI). To determine the normalized luciferase value, average luciferase activity for no virus wells were first subtracted and then the luciferase signals were normalized to the average luciferase activity for no inhibitor wells. 


\section{EXTENDED DATA}

417
a)

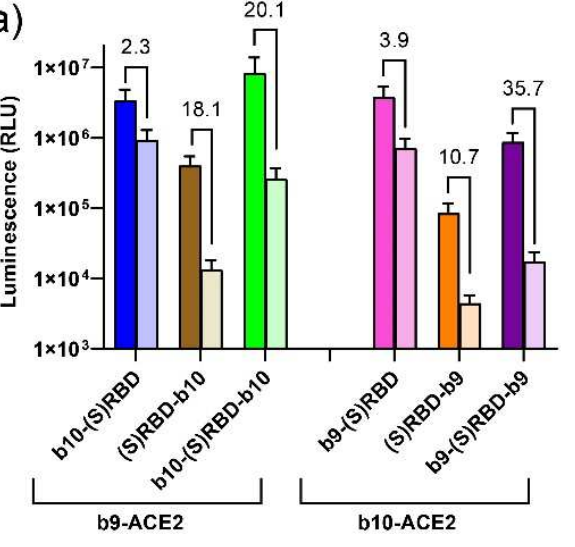

b)

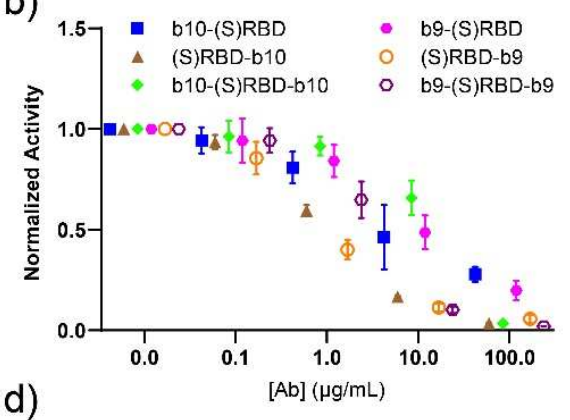

c)

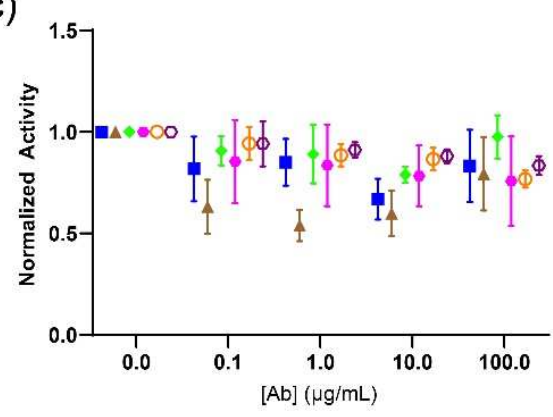

Extended Data Fig 1. Specificity of RBD binder pair in simulated human serum and IC50 values of each binder pair. a) Comparison of signals between $0 \mu \mathrm{g} / \mathrm{mL}$ of NAb (darker color) vs. $100 \mu \mathrm{g} / \mathrm{mL}$ of NAb (lighter color adjacent bar) from six different pairs. Although all pairs show good response, some pairs show more distinct fold-difference between without vs. with NAb as indicated by numbers above bars. b) Pairs of ACE2 binders and (S)RBD binders were screened with increasing concentrations of neutralizing Ab (NAb, Sino Biological 40592-MM57) spiked in human serum. All pairs show substantial decrease in signal with increasing concentrations of NAb, demonstrating a quantifiable dose-response. c) When each binder pair was incubated with control isotype IgG-spiked human serum (additional concentrations of IgG spiked into human serum), less than $20 \%$ inhibition from high $\operatorname{lgG}(100 \mu \mathrm{g} / \mathrm{mL}$ ) was observed in all of the pairs. d) IC50 $(\mu \mathrm{g} / \mathrm{mL})$ of the same NAb was calculated using six different binder pairs with AAT Bioquest IC50 calculator. 

RQIAPGQTGKIADYNYKLPDDFTGCVIAWNSNNLDSKVGGNYNYYYLFRKSNLKPFERDISTEIYQAGSTPCNGVEGFNCYFPLQSYGFQPTNGVGYQPYRVVVLSFELLHAPATVCGPKKSTNLVKNKCVNFGGSHHH $\mathrm{HHHH}^{*}$

MFVFLVLLPLVSSQRVQPTESIVRFPNITNLCPFGEVFNATRFASVYAWNRKRISNCVADYSVLYNSASFSTFKCYGVSPTKLNDLCFTNVYADSFVIRGDEVRQIAPGQTGKIADYNYKLPDDFTGCVIAWNSNNLDSKVGG NYNYLYRLFRKSNLKPFERDISTEIYQAGSTPCNGVEGFNCYFPLQSYGFQPTNGVGYQPYRVVVLSFELLHAPATVCGPKKSTNLVKNKCVNFGGGGSGGGSGSMLFRVTINSGGSHHHHHHHH*

MRLPGAMPALALKGELLLLSLLLLLEPQISQGGGGSMLFRVTINSGGGGSGGGSRVQPTESIVRFPNITNLCPFGEVFNATRFASVYAWNRKRISNCVADYSVLYNSASFSTFKCYGVSPTKLNDLCFTNVYADSFVIRGDEV

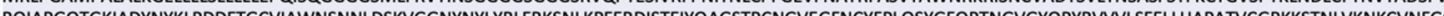
RQIAPGQTGKIADYNYKLPDDFTGCVIAW MSGSMLFRVTINSGGSHHHHHHHH* $\mathrm{HHHH}^{*}$

b10-(S)RBD RQIAPGQTGKIADYNYKLPDDFTGCVIAWNSNNIDSKVGG NYNYIYRLFRKSNIKPFERDISTEIYOAGSTPCNGVEGFNCYFPLOSYGFOPTNGVGYOPYRWVISFELHAPATVCGPKKSTNIVKNKCVNFGGSHHH

(S)RBD-b10 MFVFLVLLPLVSSQRVQPTESIVRFPNITNLCPFGEVFNATRFASVYAWNRKRISNCVADYSVLYNSASFSTFKCYGVSPTKLNDLCFTNVYADSFVIRGDEVRQIAPGQTGKIADYNYKLPDDFTGCVIAWNSNNLDSKVGG NYNYLYRLFRKSNLKPFERDISTEIYQAGSTPCNGVEGFNCYFPLQSYGFQPTNGVGYQPYRVVVLSFELLHAPATVCGPKKSTNLVKNKCVNFGGGGSGGSVSGWRLFKKISGGSHHHHHHHH*

MRLPGAMPALALKGELLLLSLLLLLEPQISQGGGVSGWRLFKKISGGGGSGGGSRVQPTESIVRFPNITNLCPFGEVFNATRFASVYAWNRKRISNCVADYSVLYNSASFSTFKCYGVSPTKLNDLCFTNVYADSFVIRGDEV MRLPGAMPALALKGELLLLSLLLLEPQISQGGGVSGWRLFKKISGGGGSGGGSRVQPTESIVRFPNITNLCPFGEVFNATRFASVYAWNRKRISNCVADYSVLYNSASFSTFKCYGVSPTKLNDLCFTNVYADSFVIRGDEV
b10-(S)RBD-b10 RQIAPGQTGKIADYNYKLPDDFTGCVIAWNSNNLDSKVGGNYNYLYRLFRKSNLKPFERDISTEIYQAGSTPCNGVEGFNCYFPLQSYGFQPTNGVGYQPYRVVVLSFELLHAPATVCGPKKSTNLVKNKCVNFGGGGSGC GSVSGWRLFKKISGGSHHHHHHHH*

MRLPGAMPALALKGELLLLSLLLLLEPQISQGGGVSGWRLFKKISGGGGSGGGSGGGGSGGGSCVNLTTRTQLPPAYTNSFTRGVYYPDKVFRSSVLHSTQDLFLPFFSNVTWFHAIHVSGTNGTKRFDNPVLPFNDGVYF ASTEKSNIIRGWIFGTTLDSKTQSLLIVNNATNVVIKVCEFQFCNDPFLGVYYHKNNKSWMESEFRVYSSANNCTFEYVSQPFLMDLEGKQGNFKNLREFVFKNIDGYFKIYSKHTPINLVRDLPQGFSALEPLVDLPIGINITR FQTLLALHRSYLTPGDSSSGWTAGAAAYYVGYLQPRTFLLKYNENGTITDAVDCALDPLSETKCTLKSFTVEKGIYQTSNFRVQPTESIVRFPNITNLCPFGEVFNATRFASVYAWNRKRISNCVADYSVLYNSASFSTFKCYG VSPTKLNDLCFTNVYADSFVIRGDEVRQIAPGQTGKIADYNYKLPDDFTGCVIAWNSNNLDSKVGGNYNYLYRLFRKSNLKPFERDISTEIYQAGSTPCNGVEGFNCYFPLQSYGFQPTNGVGYQPYRVVVLSFELLHAPAT VCGPKKSTNLVKNKCVNFNFNGLTGTGVLTESNKKFLPFQQFGRDIADTTDAVRDPQTLEILDITPCSFGGVSVITPGTNTSNQVAVLYQDVNCTEVPVAIHADQLTPTWRVYSTGSNVFQTRAGCLIGAEHVNNSYECDIP IGAGICASYQTQTNSPGSASSVASQSIIAYTMSLGAENSVAYSNNSIAIPTNFTISVTTEILPVSMTKTSVDCTMYICGDSTECSNLLLQYGSFCTQLNRALTGIAVEQDKNTQEVFAQVKKQIYKTPPIKDFGGFNFSQILPDPSK PSKRSFIEDLLFNKVTLADAGFIKQYGDCLGDIAARDLICAQKFNGLTVLPPLLTDEMIAQYTSALLAGTITSGWTFGAGAALQIPFAMQMAYRFNGIGVTQNVLYENQKLIANQFNSAIGKIQDSLSSTASALGKLQDVVNQ NAQALNTLVKOISSNFGAISSVLNDILSRLDPPEAEVOIDRLITGRLOSLOTYVTOQLRAAEIRASANLAATKMSECVLGOSKRVDFCGKGYHLMSFPOSAPHGVVFLHVTYVPAOEKNFTTAPAICHDGKAHFPREGVFV SNGTHWFVTORNFYEPQITTDNTFVSGNCDYIGIVNNTVYDPLOPELDSFKEELDKYFKNHTSPDVDIGDISGINASWNIOKEIDRINEVAKNLNESUDDOELGKYEQYIKWPGGSGGYIPEAPRDGOAYVKDGEW LLSTFLGGSHHHHHHHH*

MRLPGAMPALALKGELLLLSLLLLEPQISQGGGGSMLFRVTINSGGGGSGGGSAAQSTIEEQAKTFLDKFNHEAEDLFYQSSLASWNYNTNITEENVQNMNNAGDKWSAFLKEQSTLAQMYPLQEIQNLTVKLQLQAL פ9-ACE2 QQNGSSVLSEDKSKRLNTILNTMSTIYSTGKVCNPDNPQECLLLEPGLNEIMANSLDYNERLWAWESWRSEVGKQLRPLYEEYVVLKNEMARANHYEDYGDYWRGDYEVNGVDGYDYSRGQLIEDVEHTFEEIKPLYEH (9 G/S linker) LHAYVRAKLMNAYPSYISPIGCLPAHLLGDMWGRFWTNLYSLTVPFGQKPNIDVTDAMVDQAWDAQRIFKEAEKFFVSVGLPNMTQGFWENSMLTDPGNVQKAVCHPTAWDLGKGDFRILMCTKVTMDDFLTAH LHAYVRAKLMNAYPSYISPIGCLPAHLLGDMWGRFWTNLYSLTVPFGQKPNIDVTDAMVDQAWDAQRIFKEAEKFFVSVGLPNMTQGFWENSMLTDPGNVQKAVCHPTAWDLGKGDFRILMCTKVTMDDFLTAH
HEMGHIQYDMAYAAQPFLLRNGANEGFHEAVGEIMSLSAATPKHLKSIGLLSPDFQEDNETEINFLLKQALTIVGTLPFTYMLEKWRWMVFKGEIPKDQWMKKWWEMKREIVGVVEPVPHDETYCDPASLFHVSNDY W SFIRYYTRTLYQFQFOEALCOAAKHEGPLHKCDISNSTEAGQKLFNMLRLGKSEPWTLALENVVGAKNMNVRPLLNYFEPLFTWLKDQNKNSFVGWSTDWSPYAGGSHHHHHHHH* MRLPGAMPALALKGELLLLSLLLLLPQISQGGGVSGWRLFKKISGGGGSGGGSAAQSTIEEQAKTFLDKFNHEAEDLFYQSSLASWNYNTNITEENVQNMNNAGDKWSAFLKEQSTLAQMYPLQEIQNLTVKLQLQAL 10-ACE2 QQNGSSVLSEDKSKRLNTILNTMSTIYSTGKVCNPDNPQECLLLEPGLNEIMANSLDYNERLWAWESWRSEVGKQLRPLYEEYVLKNEMARANHYEDYGDYWRGDYEVNGVDGYDYSRGQLIEDVEHTFEEIKPLYEH

(9 G/S linker) LHAYVRAKLMNAYPSYISPIGCLPAHLLGDMWGRFWTNLYSLTVPFGQKPNIDVTDAMVDQAWDAQRIFKEAEKFFVSVGLPNMTQGFWENSMLTDPGNVQKAVCHPTAWDLGKGDFRILMCTKVTMDDFLTAH HEMGHIQYDMAYAAQPFLLRNGANEGFHEAVGEIMSLSAATPKHLKSIGLLSPDFEDNETEINFLLKQALTIVGTLPFTYMLEKWRWMVFKGEIPKDQWMKKWWEMKREIVGVVEPVP
SFIRYYTRTLYQFQFQEALCQAAKHEGPLHKCDISNSTEAGQKLFNMLRLGKSEPWTLALENVVGAKNMNVRPLLNYFEPLFTWLKDQNKNSFVGWSTDWSPYAGGSHHHHHHHH* SFIRYYTRTLYQFQFQEALCQAAKHEGPLHKCDISNSTEAGQKLFNMLRLGKSEPWTLALENVVGAKNMNVRPLLNYFEPLFTWLKDQNKNSFVGWSTDWSPYAGGSHHHHHHHH*
MRLPGAMPALALKGELLLLSLLLLLEPQISQGGGGSMLFRVTINSGGGGSGGGSGGGGSGGGSAAQSTIEEQAKTFLDKFNHEAEDLFYSSLASWNYNTNITEENVQNMNNAGDKWSAFLKEQSTLAQMYPLQEIQN MRLPGAMPALALKGELLLLLLLLLEPQISQGGGGSMLFRVTINSGGGGSGGSGGGGSGGGSAAQSTIEEQAKTFLDKFNHEAEDLFYQSSLASWNYNTNITEENVQNMNNAGDKWSAFLKEQSTLAQMYPLQEIQN
LTVKLQLQALQQNGSSVLSEDKSKRLNTILNTMSTIYSTGKVCNPDNNPECLLLEPGLNEIMANSLDYNERLWAWESWRSEVGKQLRPLYEEYVVLKNEMARANHYEDYGDYWRGDYEVNGVDGYDYSRGQLIEDVEH TFEEIKPLYEHLHAYVRAKLMNAYPSYISPIGCLPAHLLGDMWGRFWTNLYSLTVPFGQKPNIDVTDAMVDQAWDAQRIFKEAEKFFVSVGLPNMTQGFWENSMLTDPGNVQKAVCHPTAWDLGKGDFRILMCTKV USE In Pai

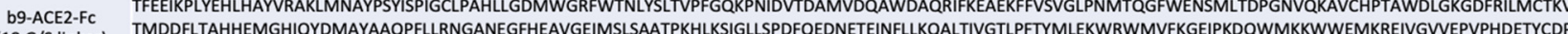
ASLFHVSNDYSFIRYYTRTLYOFOFOEALCOAAKHEGPLHKCDISNSTEAGQKLFNMLRLGKSEPWTLALENVVGAKNMNVRPLLNYFEPLFTWLKDONKNSFVGWSTDWSPYAGGSGGGGSGGGGSTCPPCPAPELI GGPSVFLFPPKPKDTLMISRTPEVTCVVVDVSHEDPEVKFNWYVDGVEVHNAKTKPREEQYNSTYRVVSVLTVLHQDWLNGKEYKCKVSNKALPAPIEKTISKAKGQPREPQVYTLPPSRDELTKNQVSLTCLVKGFYPSDI AVEWESNGQPENNYKTTPPVLDSDGSFFLYSKLTVDKSRWQQGNVFSCSVMHEALHNHYTQKSLSLSPGKGGSHHHHHHHH*

Extended Data Table 1. Amino acid sequences of the binders. Spike protein and ACE2 sequences were obtained from literature sources. Then, each binder was PCR-modified with appropriate tags and linkers to produce binders. Octa-histidine was used as the purification tag. $M$ denotes the location of the START codon and ${ }^{*}$ denotes STOP codon. PDGFRB signal peptide (RLPGAMPALALKGELLLLSLLLLLEPQISQG) was used to promote protein secretion. The sequences for b9 and b10 are GSMLFRVTINS 


\begin{tabular}{|c|c|c|c|}
\hline Alpha (B.1.1.7) & Beta (B.1.351) & Gamma (P.1) & Delta (B.1.617.2) \\
\hline & L18F & L18F & \\
\hline & & T20N & \\
\hline & & P26S & \\
\hline \multicolumn{4}{|l|}{ HV69-70del } \\
\hline & $\mathrm{D} 80 \mathrm{~A}$ & & \\
\hline & & D138Y & \\
\hline & & & G142D \\
\hline \multicolumn{4}{|l|}{ Y144del } \\
\hline & & & E154K \\
\hline & & R190S & \\
\hline & D215G & & \\
\hline & LAL242-244del & & \\
\hline & $\mathrm{R} 2461 \mathrm{I}$ & & \\
\hline & K417N & $\mathrm{K} 417 \mathrm{~T}$ & \\
\hline & & & L452R \\
\hline & E484K & E484K & $\mathrm{E} 484 \mathrm{Q}$ \\
\hline N501Y & N501Y & N501Y & \\
\hline \multicolumn{4}{|l|}{$A 570 D$} \\
\hline & D614G & & D614G \\
\hline & & H655Y & \\
\hline $\mathrm{C} 681 \mathrm{H}$ & & & P681R \\
\hline R682G & R682G & R682G & R682G \\
\hline R683S & R683S & R683S & R683S \\
\hline \multirow[t]{2}{*}{ R685S } & R685S & R685S & R685S \\
\hline & A701V & & \\
\hline \multicolumn{4}{|l|}{ T716I } \\
\hline \multicolumn{4}{|l|}{ S982A } \\
\hline K986P & K986P & K986P & K986P \\
\hline \multirow[t]{4}{*}{ V987P } & V987P & V987P & V987P \\
\hline & & T1027I & \\
\hline & & & Q1071H \\
\hline & & & H1101D \\
\hline $\mathrm{D} 1118 \mathrm{H}$ & & & \\
\hline
\end{tabular}

Extended Data Table 2. Spike protein variant mutations. Mutation information was obtained from literature sources. Additional mutations were made (R682G, R683S, R685S, K986P, and V987P) to the furin cleavage site to prevent degradation of proteins by host cell protease. Del denotes for deletion. 


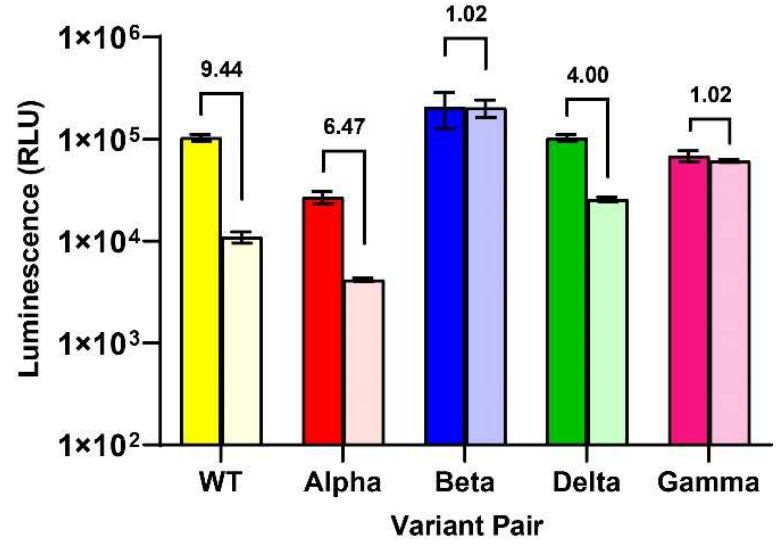

499

Extended Data Fig 2. Neutralization of full S protein variant pairs. The efficacy of $100 \mu \mathrm{gg} / \mathrm{mL} \mathrm{NAb}$ (Sino Biological, 40592 R001) was tested with variant pairs. The Alpha variant showed the most decrease in signal followed by the Delta strain.

500 Almost no neutralization was observed with the Beta or Gamma strain.

501

502

503

504

505

506

507

508

509

510

511

512

513

514

515

516

517

518

519

520

521

522

523

524

525

526

527

528

529

530

531

532

533 


\section{REFERENCES}

1. Ravi, N., Cortade, D.L., Ng, E. \& Wang, S.X. Diagnostics for SARS-CoV-2 detection: A comprehensive review of the FDA-EUA COVID-19 testing landscape. Biosensors and Bioelectronics 165, 112454 (2020).

2. Oh, H., Ahn, H. \& Tripathi, A. A Closer Look into FDA-EUA Approved Diagnostic Techniques of Covid19. ACS Infectious Diseases (2021).

3. Carter, L.J. et al. (ACS Publications, 2020).

4. Cantoni, D., Mayora-Neto, M. \& Temperton, N. The role of pseudotype neutralization assays in understanding SARS CoV-2. Oxford open immunology 2, iqab005 (2021).

5. Ferrara, F. \& Temperton, N. Pseudotype neutralization assays: from laboratory bench to data analysis. Methods and protocols 1, 8 (2018).

6. Muruato, A.E. et al. A high-throughput neutralizing antibody assay for COVID-19 diagnosis and vaccine evaluation. Nature communications 11, 1-6 (2020).

7. Abe, K.T. et al. A simple protein-based surrogate neutralization assay for SARS-CoV-2. JCl insight 5 (2020).

8. Tan, C.W. et al. A SARS-CoV-2 surrogate virus neutralization test based on antibody-mediated blockage of ACE2-spike protein-protein interaction. Nature biotechnology 38, 1073-1078 (2020).

9. Byrnes, J.R. et al. Competitive SARS-CoV-2 serology reveals most antibodies targeting the spike receptor-binding domain compete for ACE2 binding. MSphere 5, e00802-00820 (2020).

10. Azad, T. et al. SARS-CoV-2 S1 NanoBiT: A nanoluciferase complementation-based biosensor to rapidly probe SARS-CoV-2 receptor recognition. Biosensors and Bioelectronics 180, 113122 (2021).

11. Yao, Z. et al. A homogeneous split-luciferase assay for rapid and sensitive detection of anti-SARS CoV-2 antibodies. Nature communications 12, 1-8 (2021).

12. Dixon, A.S., Kim, S.J., Baumgartner, B.K., Krippner, S. \& Owen, S.C. A tri-part protein complementation system using antibody-small peptide fusions enables homogeneous immunoassays. Scientific reports 7, 1-13 (2017).

13. Kim, S.J., Dixon, A.S., Adamovich, P.C., Robinson, P.D. \& Owen, S.C. Homogeneous Immunoassay Using a Tri-Part Split-Luciferase for Rapid Quantification of Anti-TNF Therapeutic Antibodies. ACS sensors (2021).

14. Kim, S.J., Dixon, A.S. \& Owen, S.C. Split-enzyme Immunoassay to Monitor EGFR-HER2 Heterodimerization on Cell Surfaces. Acta Biomaterialia (2021).

15. Lan, J. et al. Structure of the SARS-CoV-2 spike receptor-binding domain bound to the ACE2 receptor. Nature 581, 215-220 (2020).

16. Sahin, U. et al. COVID-19 vaccine BNT162b1 elicits human antibody and TH $1 \mathrm{~T}$ cell responses. Nature 586, 594-599 (2020).

17. Min, L. \& Sun, Q. Antibodies and Vaccines Target RBD of SARS-CoV-2. Frontiers in Molecular Biosciences 8, 247 (2021).

18. Harvey, W.T. et al. SARS-CoV-2 variants, spike mutations and immune escape. Nature Reviews Microbiology 19, 409-424 (2021).

19. Khateeb, J., Li, Y. \& Zhang, H. Emerging SARS-CoV-2 variants of concern and potential intervention approaches. Critical Care 25, 1-8 (2021).

20. Dai, L. \& Gao, G.F. Viral targets for vaccines against COVID-19. Nature Reviews Immunology 21, 7382 (2021).

21. Hsieh, C.-L. et al. Structure-based design of prefusion-stabilized SARS-CoV-2 spikes. Science 369, 1501-1505 (2020).

22. Benton, D.J. et al. Receptor binding and priming of the spike protein of SARS-CoV-2 for membrane fusion. Nature 588, 327-330 (2020). 
581

582

583

584

585

586

587

588

589

590

591

592

593

594

595

596

597

598

599

600

601

602

603

604

605

606

607

608

609

610

611

612

613

614

615

616

617

618

619

620

621

622

623

23. Xiao, T. et al. A trimeric human angiotensin-converting enzyme 2 as an anti-SARS-CoV-2 agent. Nature Structural \& Molecular Biology 28, 202-209 (2021).

24. Hoffmann, M., Kleine-Weber, H. \& Pöhlmann, S. A multibasic cleavage site in the spike protein of SARS-CoV-2 is essential for infection of human lung cells. Molecular cell 78, 779-784. e775 (2020).

25. Xia, S. et al. The role of furin cleavage site in SARS-CoV-2 spike protein-mediated membrane fusion in the presence or absence of trypsin. Signal transduction and targeted therapy 5, 1-3 (2020).

26. Dispinseri, S. et al. Neutralizing antibody responses to SARS-CoV-2 in symptomatic COVID-19 is persistent and critical for survival. Nature communications 12, 1-12 (2021).

27. Tea, F. et al. SARS-CoV-2 neutralizing antibodies; longevity, breadth, and evasion by emerging viral variants. medRxiv, 2020.2012. 2019.20248567 (2021).

28. Greaney, A.J. et al. Antibodies elicited by mRNA-1273 vaccination bind more broadly to the receptor binding domain than do those from SARS-CoV-2 infection. Science Translational Medicine (2021).

29. Skelly, D.T. et al. Two doses of SARS-CoV-2 vaccination induce robust immune responses to emerging SARS-CoV-2 variants of concern. Nature communications 12, 1-12 (2021).

30. Israel, A. et al. Large-scale study of antibody titer decay following BNT162b2 mRNA vaccine or SARS-CoV-2 infection. medRxiv (2021).

31. Khoury, D.S. et al. Neutralizing antibody levels are highly predictive of immune protection from symptomatic SARS-CoV-2 infection. Nature medicine, 1-7 (2021).

32. Lu, Y. et al. Advances in Neutralization Assays for SARS-CoV-2. Scandinavian Journal of Immunology 94, e13088 (2021).

33. Dashdorj, N.J. et al. Direct Comparison of Antibody Responses to Four SARS-CoV-2 Vaccines in Mongolia. Cell Host \& Microbe (2021).

34. Amanat, F. et al. An in vitro microneutralization assay for SARS-CoV-2 serology and drug screening. Current protocols in microbiology 58, e108 (2020).

35. Riepler, L. et al. Comparison of Four SARS-CoV-2 Neutralization Assays. Vaccines 9, 13 (2021).

36. Nayak, K. et al. Characterization of neutralizing versus binding antibodies and memory $B$ cells in COVID-19 recovered individuals from India. Virology 558, 13-21 (2021).

37. Lu, H., Stratton, C.W. \& Tang, Y.W. An evolving approach to the laboratory assessment of COVID19. Journal of medical virology 92, 1812-1817 (2020).

38. Niu, L., Wittrock, K.N., Clabaugh, G.C., Srivastava, V. \& Cho, M.W. A Structural Landscape of Neutralizing Antibodies Against SARS-CoV-2 Receptor Binding Domain. Frontiers in Immunology 12 (2021).

39. Yan, R. et al. Structural basis for the different states of the spike protein of SARS-CoV-2 in complex with ACE2. Cell research 31, 717-719 (2021).

40. Kyriakidis, N.C., López-Cortés, A., González, E.V., Grimaldos, A.B. \& Prado, E.O. SARS-CoV-2 vaccines strategies: a comprehensive review of phase 3 candidates. npj Vaccines 6, 1-17 (2021).

41. Krammer, F. SARS-CoV-2 vaccines in development. Nature 586, 516-527 (2020).

42. Samrat, S.K., Tharappel, A.M., Li, Z. \& Li, H. Prospect of SARS-CoV-2 spike protein: Potential role in vaccine and therapeutic development. Virus research, 198141 (2020).

43. Zhang, L. et al. SARS-CoV-2 spike-protein D614G mutation increases virion spike density and infectivity. Nature communications 11, 1-9 (2020). 